\title{
Comparative gene expression profiling of placentas from patients with severe pre- eclampsia and unexplained fetal growth restriction
}

Haruki Nishizawa ${ }^{1 *}$, Sayuri Ota², Machiko Suzuki², Takema Kato², Takao Sekiya' ${ }^{1}$, Hiroki Kurahashi ${ }^{2}$ and Yasuhiro Udagawa ${ }^{1}$

\begin{abstract}
Background: It has been well documented that pre-eclampsia and unexplained fetal growth restriction (FGR) have a common etiological background, but little is known about their linkage at the molecular level. The aim of this study was to further investigate the mechanisms underlying pre-eclampsia and unexplained FGR.

Methods: We analyzed differentially expressed genes in placental tissue from severe pre-eclamptic pregnancies $(n=8)$ and normotensive pregnancies with or $(n=8)$ without FGR $(n=8)$ using a microarray method.

Results: A subset of the FGR samples showed a high correlation coefficient overall in the microarray data from the pre-eclampsia samples. Many genes that are known to be up-regulated in pre-eclampsia are also up-regulated in FGR, including the anti-angiogenic factors, FLT1 and ENG, believed to be associated with the onset of maternal symptoms of pre-eclampsia. A total of 62 genes were found to be differentially expressed in both disorders. However, gene set enrichment analysis for these differentially expressed genes further revealed higher expression of TP53-downstream genes in pre-eclampsia compared with FGR. TP53-downstream apoptosis-related genes, such as $B C L 6$ and $B A X$, were found to be significantly more up-regulated in pre-eclampsia than in FGR, although the caspases are expressed at equivalent levels.
\end{abstract}

Conclusions: Our current data indicate a common pathophysiology for FGR and pre-eclampsia, leading to an upregulation of placental anti-angiogenic factors. However, our findings also suggest that it may possibly be the excretion of these factors into the maternal circulation through the TP53-mediated early-stage apoptosis of trophoblasts that leads to the maternal symptoms of pre-eclampsia.

\section{Background}

Pre-eclampsia is one of the most common and potentially serious pregnancy-associated disorders and is a principal cause of maternal morbidity, accounting for almost $15-20 \%$ of pregnancy-related mortalities [1]. Preeclampsia is not a simple complication of pregnancy, but is a syndrome involving multiple organ failure including that of the liver, kidney, lung, and the coagulatory and neural systems. The prognosis for both the

\footnotetext{
* Correspondence: nharuki@fujita-hu.ac.jp

'Department of Obstetrics and Gynecology, Fujita Health University School of Medicine, Fujita Health University, Toyoake, Japan

Full list of author information is available at the end of the article
}

mother and fetus in cases of severe pre-eclampsia is poorer than generally expected, particularly in early onset cases $(<34$ weeks of gestation) [2]. Although these patients are generally treated for prevention of seizures and control of hypertension, the lack of understanding of the precise etiology of pre-eclampsia has hindered the development of preventive and therapeutic measures to treat this disease based on its etiology. Since the risks of maternal multi-organ dysfunction and fetal distress are higher in the early onset forms of this disorder, it has been recommended that the fetus should be delivered during gestational weeks 32-34 in such cases [1].

\section{Biomed Central}


There is now an emerging consensus that pre-eclampsia is a complex polygenetic trait in which maternal and fetal genes, as well as environmental factors, are involved. However, the pathogenetic process involves numerous factors such as oxidative stress, endothelial dysfunction, vasoconstriction, metabolic changes, thrombotic disorders and inflammatory responses, and the precise underlying mechanisms have remained elusive $[3,4]$. It has also been formally considered, however, that the placenta plays a primary role in the etiology of this disorder. In support of this idea is the observation that patients with pre-eclampsia recover from clinical symptoms of the disorder just after the delivery of the fetus and placenta, that pre-eclampsia occurs in patients with a hydatidiform mole characterized by trophoblast hyperplasia in the absence of any tissues of fetal origin, and also that paternity is a significant risk factor for preeclampsia [5]. Several recent lines of evidence have also indicated that placenta-derived anti-angiogenic factors, such as soluble fms-like tyrosine kinase-1 and soluble endoglin, significantly contribute to the onset of preeclampsia [6,7].

Fetal growth restriction (FGR) is another clinical entity that increases the risk of perinatal morbidity and mortality and can result from heterogeneous causes, including maternal, fetal and placental factors. FGR may result from defects in endogenous developmental and growth factors, whereas a placental defect may inhibit the transport of nutrients and oxygen from mother to fetus [8]. Some forms of unexplained FGR have been etiologically linked to pre-eclampsia since they show common pathologic features in the placenta, although this assertion has remained controversial [9]. A failure of trophoblast invasion leading to abnormal shallow vascularity and impaired remodeling of the spiral arteries appears to be a common process behind these disorders [10]. Although pre-eclamptic placentas generally manifest fewer morphological changes than those of FGR cases, the placentas from early-onset cases of pre-eclampsia display substantial villous and vascular abnormalities $[11,12]$. In this context, it could be hypothesized that a subset of FGR and early-onset pre-eclampsia cases are likely to share common etiologies, and that the presence or absence of maternal risk factors determines disease manifestation, but this contention remains speculative [13].

Given the current evidence base, it is of clinical importance to compare the gene expression profiles of pre-eclampsia and FGR to further our understanding of their respective etiologies and aid in the future development of new therapies. In our current study, we have performed such global gene expression profiling via oligonucleotide microarrays of placental tissue from severe pre-eclampsia, unexplained FGR and normal pregnancies.

\section{Methods}

\section{Human subjects}

All clinical samples were collected at the Department of Obstetrics and Gynecology, Fujita Health University, Japan. Informed consent was obtained from each patient and the study protocol was approved by the Ethical Review Board for Human Genome Studies at Fujita Health University (Accession number 43 and 87, approved on February 23, 2005 and March 24, 2010, respectively). A total of 24 placental biopsies were obtained from severe pre-eclamptic pregnancies $(n=8)$ and normotensive pregnancies with $(n=8)$ or without FGR $(n=8)$. Pre-eclampsia was defined as a blood pressure of higher than $140 / 90 \mathrm{mmHg}$, with proteinuria of more than $0.3 \mathrm{~g}$ in a 24 hour collection. The pre-eclampsia was considered severe if one or more of the following criteria were present: a blood pressure of higher than $160 / 110 \mathrm{mmHg}$, or proteinuria of more than $2 \mathrm{~g}$ in a 24 hour collection [14]. FGR was diagnosed when the birth weight was below the 10th percentile of that anticipated for the given gestational age for a Japanese population [15]. Unexplained FGR was defined by the exclusion of known maternal and fetal factors including maternal systemic diseases, multiple gestation, fetal congenital infection, structural abnormalities and chromosomal abnormalities. Additionally, all FGR cases showed clinical signs of disturbed placental function such as asymmetric growth, oligohydroamnions, and/or increased pulsatility index of the umbilical artery. Normotensive subjects with or without FGR were matched for maternal and gestational ages, and for body mass index during pre-pregnancy (Table 1).

\section{Placental biopsy collection}

All of the placental biopsies, both from pre-eclamptic and normotensive pregnancies with or without FGR, were obtained following Caesarean sections. In normotensive cases, Caesarean sections were performed due to previous Caesarean sections. To avoid any effects of labor upon the gene expression profiles of the tissue samples, only placental samples that were obtained from the women who had not undergone labor were included in the study. A central area of chorionic tissue was dissected, and the maternal deciduas and amnionic membranes were removed. We then dissected $1 \mathrm{~cm}$ sections of placental villi from the four different central areas between the basal and chorionic plates. After vigorous washing of the maternal blood with saline, tissues were immediately frozen in liquid nitrogen and stored until use. 
Table 1 Clinical parameters of the study groups

\begin{tabular}{|c|c|c|c|c|c|c|}
\hline & \multirow{2}{*}{$\begin{array}{l}\text { Control } \\
(n=8)\end{array}$} & \multirow{2}{*}{$\begin{array}{c}\text { FGR } \\
(\mathrm{n}=8)\end{array}$} & \multirow{2}{*}{$\begin{array}{c}\mathrm{PE} \\
(\mathrm{n}=8)\end{array}$} & \multicolumn{3}{|c|}{$P$ Value } \\
\hline & & & & Control vs FGR & Control vs PE & FGR vs PE \\
\hline Maternal age (y) & $31.5 \pm 6.5^{a}$ & $31.4 \pm 3.7$ & $31.0 \pm 4.7$ & 0.96 & 0.86 & 0.86 \\
\hline Prepregnancy Body mass index & $21.4 \pm 2.3$ & $19.9 \pm 1.9$ & $21.7 \pm 3.7$ & 0.19 & 0.83 & 0.26 \\
\hline Gestational age at delivery (wks) & $38.1 \pm 0.8$ & $37.3 \pm 1.0$ & $34.4 \pm 1.8$ & 0.08 & $<0.01$ & $<0.01$ \\
\hline Birth weight (g) & $2891.5 \pm 309.6$ & $1765.4 \pm 483.9$ & $1666.6 \pm 441.0$ & $<0.01$ & $<0.01$ & 0.68 \\
\hline Birth weight coefficient & $1.007 \pm 0.120$ & $0.646 \pm 0.151$ & $0.778 \pm 0.103$ & $<0.01$ & $<0.01$ & 0.06 \\
\hline Placental weight (g) & $571.4 \pm 151.0$ & $329.4 \pm 61.3$ & $341.3 \pm 59.4$ & $<0.01$ & $<0.01$ & 0.70 \\
\hline Systolic BP (mmHg) & $111.3 \pm 11.1$ & $123.3 \pm 14.5$ & $160.6 \pm 10.0$ & 0.08 & $<0.01$ & $<0.01$ \\
\hline Diastolic BP (mmHg) & $66.9 \pm 8.7$ & $77.0 \pm 11.9$ & $105.3 \pm 9.6$ & 0.07 & $<0.01$ & $<0.01$ \\
\hline Proteinuria $(\%)^{b}$ & 0 & 0 & 100 & n.s. & $<0.01$ & $<0.01$ \\
\hline$U m A P^{c}$ & $0.76 \pm 0.10$ & $1.11 \pm 0.32$ & $1.12 \pm 0.34$ & 0.01 & 0.01 & 0.98 \\
\hline
\end{tabular}

${ }^{\text {a }}$ Data are given as the mean \pm standard deviation (SD)

$\mathrm{b} \geq 5 \mathrm{~g}$ in a 24 hour collection

c Pulsatility index of the umbilical artery

\section{RNA extraction}

Total RNA was extracted from the chorionic villous tissues with an RNeasy mini-kit (Qiagen Inc., Valencia, CA) in accordance with the manufacturer's instructions. The quality of the RNA samples was determined by electrophoresis through denaturing agarose gels and staining with ethidium bromide. We measured the intensities of $28 \mathrm{~S}$ and $18 \mathrm{~S}$ rRNAs and a higher than 2:1 ratio was considered the benchmark for intact RNA. The RNA was quantified and evaluated for purity by UV spectrophotometry. RNA samples obtained from four different areas of a single placenta were mixed prior to expression analyses. To further assess the quality of the RNA, all specimens were subjected to expression analysis of the housekeeping gene, glyceraldehyde-3-phosphate dehydrogenase (GAPDH), using conventional RTPCR. To test for possible contamination by maternal blood, the expression of a leukocyte-specific gene (leukocyte common antigen; LCA) was also examined using conventional semi-quantitative RT-PCR [16].

\section{Microarray analysis}

Microarray experiments were performed using the Affymetrix GeneChip system (Affymetrix, Santa Clara, CA). Briefly, approximately $1 \mu \mathrm{g}$ of each total RNA sample was used for double strand cDNA synthesis. cRNA was synthesized by in vitro transcription followed by sense-strand cDNA synthesis using the Ambion Whole Transcript Expression Kit (Applied Biosystems, Foster City, CA). After fragmentation into $\sim 200 \mathrm{bp}$ strands with uracil DNA glycosylase, synthesized sense-strand cDNAs were end-labeled with biotin, and then hybridized to an Affymetrix Human Exon 1.0 ST Array. Signal intensities were amplified via secondary staining with a biotin-labeled antistreptavidin antibody followed by phycoerythrin-streptavidin staining. Fluorescent image arrays were obtained using a GeneChip Scanner 3000 (Affymetrix).
Microarray data analyses were performed using Microsoft Excel, Partek Genomics Suite 6.5 (Partek Inc., St. Louis, MO) and Genespring GX11 (Silicon Genetics, Redwood City, CA). All data were subjected to per chip and per gene normalization, quantile normalization and quality control, and a total of 24,805 genes were used for further analysis. Microarray data were deposited in the GEO database with the detailed hybridization information according to the MIAME guidelines and assigned the accession number GSE24129 [17]. To analyze the correlation of microarray data pairs, we used the Pearson's correlation coefficient. In addition, we adopted the non-negative matrix factorization (NMF) method, which is an unsupervised classification algorithm $[18,19]$. The NMF method was performed using the NMF package in the $\mathrm{R}$ system. $K=2-5$ indicates the number of subclasses modeled. To identify specific pathways that may be involved in the progression of preeclampsia or FGR, we performed standard gene ontology (GO) analysis using the Gene Spring software. We also performed gene set enrichment analysis (GSEA), a computational method that determines whether defined sets of genes show statistically significant, concordant differences between two biological states [20,21]. For this analysis we used GSEA v2.06 software from the Broad Institute [22]. Gene sets were downloaded from the Molecular Signatures Database (MSigDB) of this web site. We used the $\mathrm{C} 2$ curated catalogue of functional gene sets to select significant gene sets. A false discovery rate (FDR) of less than 0.25 and $P$ values of less than 0.001 were considered significant.

\section{Real-time RT-PCR}

To validate the microarray data for selected genes, we performed quantitative real-time RT-PCR (qRT-PCR) analysis using the Taqman System (Applied Biosystems, Foster City, CA). The Superscript First-strand Synthesis 
System for RT-PCR (Invitrogen, Carlsbad, CA) with random primers was used to produce single stranded cDNA templates. A housekeeping gene, $A C T B$, was used to normalize for mRNA levels because its expression levels among the samples were stable. All RT-PCR reactions were performed in triplicate in a final volume of $25 \mu \mathrm{l}$. The cycling conditions used for PCR amplification were $2 \mathrm{~min}$ at $50^{\circ} \mathrm{C}, 30 \mathrm{~min}$ at $60^{\circ} \mathrm{C}$ and $1 \mathrm{~min}$ at $95^{\circ} \mathrm{C}$ for RT, followed by 40 cycles of $15 \mathrm{sec}$ at $95^{\circ} \mathrm{C}$ and 1 $\min$ at $60^{\circ} \mathrm{C}$. For qRT-PCR, we increased the number of samples in addition to the original 24 samples such that a total of 41 pre-eclampsia, 16 FGR and 45 normotensive pregnancies were analyzed.

\section{Statistical analysis}

Statistical comparisons between groups were performed using the Student's $t$ test and one-way analysis of variance (ANOVA) and differences were considered to be significant at $P<0.05$.

\section{Results}

We compared the global gene expression profiles of human placentas from pre-eclamptic and unexplained
FGR cases using oligonucleotide microarrays. Eight samples were used from each of the patient groups and a normotensive control group. To perform an overview of the expression profiles of these samples, we first analyzed the correlation coefficient for the overall microarray data for each sample pair. Comparisons of the samples from any two normotensive controls showed good concordance and a high correlation coefficient (mean correlation coefficient: 0.980; Figure 1A). In contrast, a lack of concordance was found between the normotensive and disease samples (control versus preeclampsia, 0.967; control versus FGR, 0.965), indicating that the expression of numerous genes is altered in the placenta upon the onset of pre-eclampsia and FGR (Figure $1 \mathrm{~A})$. In the pre-eclamptic samples, most sample pairing (FGR1-6) also showed a high correlation coefficient (0.976), whereas less correlation was observed between FGR samples (0.956), raising a possibility of heterogeneous pathophysiology for FGR. Notably also, a subset of FGR samples (FGR 7 and FRG8) showed high correlation coefficient with the pre-eclampsia samples (0.977), suggestive of a common etiological background.

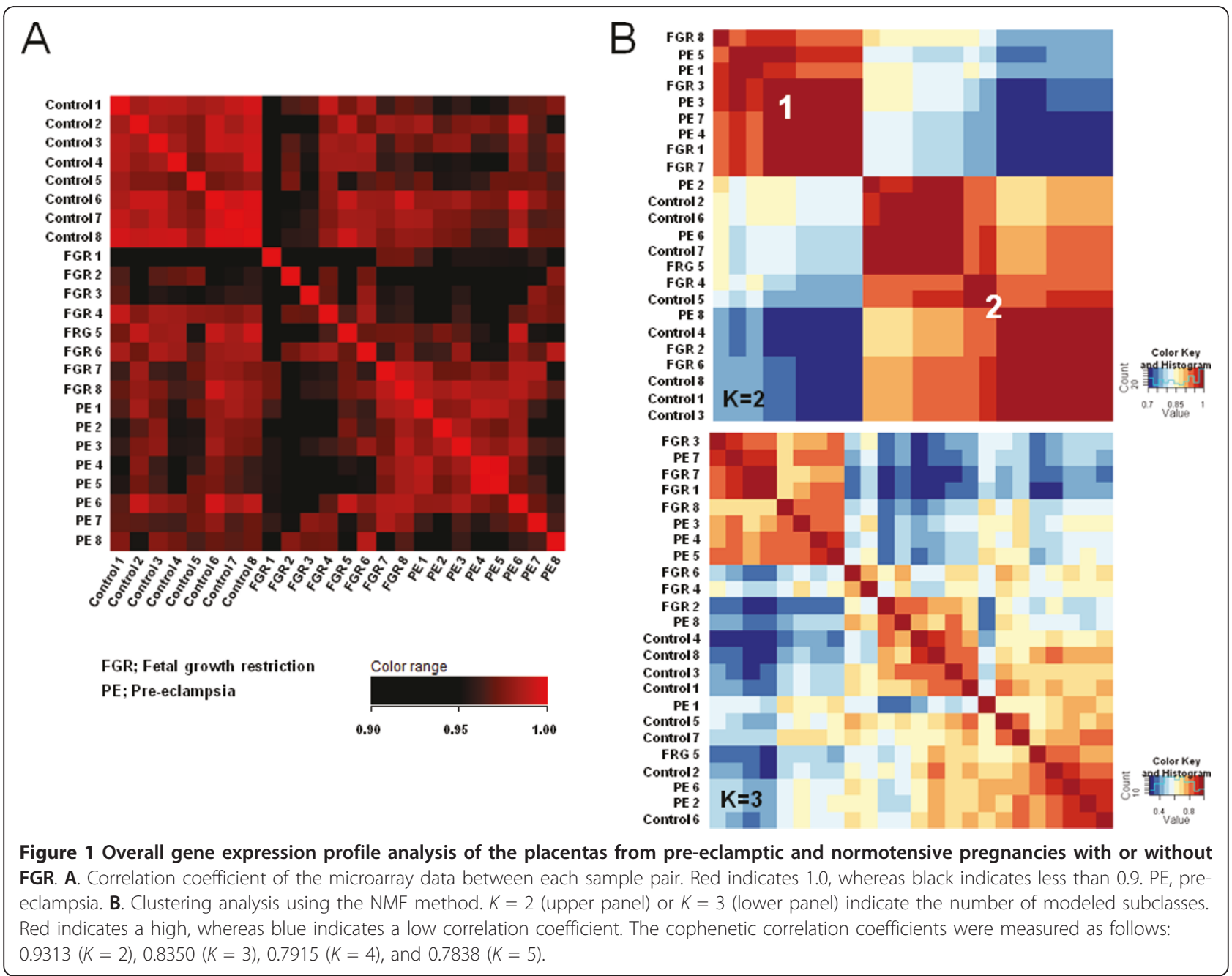


This might also be attributable to the fact that preeclamptic women delivered newborns with lower birth weight percentiles (Table 1).

To further analyze the correlations for each sample pair, we employed the NMF method to classify the samples based on the overall microarray data. Based on the cophenetic correlation coefficient (coph) calculated for each experiment, $K=2$ showed the highest value (coph $=0.9313$ ), indicating that NMF class assignment for $K=$ 2 was the most robust. In addition, whereas all of the normotensive controls were classified as Group 2, most of the pre-eclampsia samples were classified as Group 1. A subset of the FGR samples was also classified as Group 1, suggesting a common pathophysiology with pre-eclampsia for these cases (Figure 1B).

To identify differentially expressed genes in a statistically significant manner, we performed ANOVA and fold-change analysis of the data obtained from each sample group. The gene list obtained from a class comparison between the normotensive control and preeclamptic pregnancies $(P<0.05)$ was filtered to identify candidates for which the expression levels differed by at least 1.5 -fold between the two groups. We thereby identified a total of 245 genes. Similar analysis between the control pregnancy and FGR groups identified a total of 252 genes, including 62 genes in common with the gene set for pre-eclampsia (Figure 2A). As expected, INHBA, INHA and FLRG (FSTL3) were found in the pre-eclampsia gene set only, consistent with their previously described association with this disease [23,24]. Our current data were also mainly consistent with our earlier findings [16]. However, many genes that had been reported previously to be upregulated in pre-eclampsia, such as $L E P, C G B, C R H$ and PAPP-A2 [25,26], were identified in the gene sets for both pre-eclampsia and unexplained FGR in our present analyses (Tables 2, 3

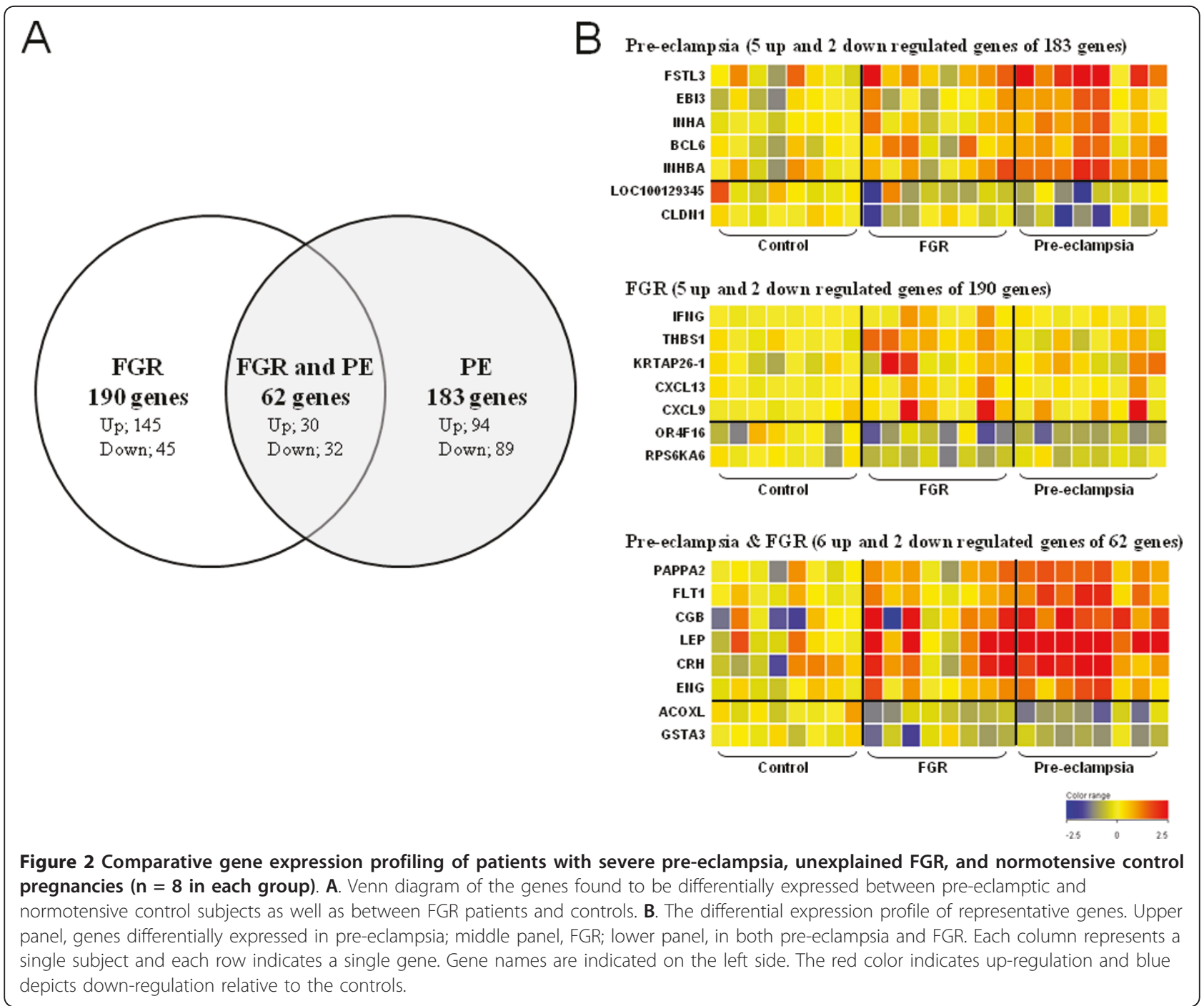


Table 2 The most highly differentially expressed genes in the pre-eclampsia samples

\begin{tabular}{|c|c|c|c|}
\hline Gene name & Genbank & Fold-Change & $P$ Value \\
\hline \multicolumn{4}{|c|}{ Up-regulated genes } \\
\hline FSTL3 & NM_005860 & 3.30 & 0.0028 \\
\hline SERPINA3 & NM_001085 & 2.90 & 0.0137 \\
\hline INHBA & NM_002192 & 2.42 & 0.0004 \\
\hline $\mathrm{EBI} 3$ & NM_005755 & 2.08 & 0.0016 \\
\hline TREM1 & NM_018643 & 2.05 & 0.0062 \\
\hline $\mathrm{BCL6}$ & NM_001706 & 2.02 & 0.0024 \\
\hline RNU2-1 & NR_002716 & 1.99 & 0.0013 \\
\hline $\mathrm{SLCO} 2 \mathrm{~A} 1$ & NM_005630 & 1.91 & 0.0053 \\
\hline INHA & NM_002191 & 1.90 & 0.0019 \\
\hline SNORD115-5 & NR_003297 & 1.87 & 0.0481 \\
\hline PVRL4 & NM_030916 & 1.80 & 0.0030 \\
\hline GBA & NM_000157 & 1.80 & 0.0022 \\
\hline DERL3 & NM_198440 & 1.78 & $<0.0001$ \\
\hline KRT19 & NM_002276 & 1.75 & 0.0071 \\
\hline LOC728220 & ENST00000391570 & 1.75 & 0.0369 \\
\hline \multicolumn{4}{|c|}{ Down-regulated genes } \\
\hline CLDN1 & NM_021101 & 2.23 & 0.0051 \\
\hline LOC100129345 & XM_001724751 & 2.18 & 0.0165 \\
\hline FAM164A & AF151820 & 2.15 & 0.0003 \\
\hline C20orf69 & BC118988 & 2.00 & 0.0011 \\
\hline ZNF117 & NM_015852 & 2.00 & 0.0044 \\
\hline ANKRD20B & NR_003366 & 1.98 & 0.0230 \\
\hline PART1 & AF163475 & 1.95 & $<0.0001$ \\
\hline DKFZP434B2016 & AL137655 & 1.94 & 0.0138 \\
\hline $\mathrm{C} 7$ & NM_000587 & 1.74 & 0.0224 \\
\hline PDGFD & NM_025208 & 1.74 & 0.0070 \\
\hline LEPREL1 & NM_018192 & 1.74 & $<0.0001$ \\
\hline HSD17B1 & NM_000413 & 1.74 & $<0.0001$ \\
\hline ABCG2 & NM_004827 & 1.68 & 0.0069 \\
\hline OR51B5 & NM_001005567 & 1.67 & 0.0003 \\
\hline $\mathrm{CFH}$ & NM_000186 & 1.66 & 0.0372 \\
\hline
\end{tabular}

and 4, Figure 2B, Additional file 1, Table S1). Interestingly, FLT1 and ENG, which are likely to be associated with the maternal symptoms of pre-eclampsia [6,7], were also found to be significantly up-regulated in both pre-eclampsia and unexplained FGR in our current study. Our present data thus also support the hypothesis that pre-eclampsia and a subset of unexplained FGR share a common background etiology.

To then investigate the differences between the biological processes underlying the development of preeclampsia and unexplained FGR, we first performed standard GO analyses, which did not reveal any specific biological processes or molecular functions for these disorders (Additional file 2, Tables S2 and Additional file 3, Tables S3). Next, we performed GSEA analysis to identify any gene sets that show significant differences for each sample group. The only significant
Table 3 The most highly differentially expressed genes in the FGR samples

\begin{tabular}{|c|c|c|c|}
\hline Gene name & Genbank & Fold-Change & $P$ Value \\
\hline \multicolumn{4}{|c|}{ Up-regulated genes } \\
\hline CXCL9 & NM_002416 & 2.44 & 0.0373 \\
\hline KRTAP26-1 & NM_203405 & 1.91 & 0.0400 \\
\hline LOX & NM_002317 & 1.88 & 0.0020 \\
\hline CXCL13 & NM_006419 & 1.74 & 0.0177 \\
\hline FPR3 & NM_002030 & 1.73 & 0.0365 \\
\hline FLJ11827 & XR_040865 & 1.71 & 0.0113 \\
\hline IFNG & NM_000619 & 1.70 & 0.0195 \\
\hline RGS1 & NM_002922 & 1.69 & 0.0092 \\
\hline THBS1 & NM_003246 & 1.90 & 0.0013 \\
\hline GZMK & NM_002104 & 1.67 & 0.0206 \\
\hline CYR61 & NM_001554 & 1.65 & 0.0231 \\
\hline MSR1 & NM_002445 & 1.63 & 0.0384 \\
\hline$|F| 44 L$ & NM_006820 & 1.63 & 0.0347 \\
\hline TIMP1 & NM_003254 & 1.62 & 0.0263 \\
\hline $\mathrm{C} 1 \mathrm{QB}$ & NM_000491 & 1.60 & 0.0440 \\
\hline \multicolumn{4}{|c|}{ Down-regulated genes } \\
\hline OR4F16 & NM_001005277 & 1.85 & 0.0192 \\
\hline RPS6KA6 & NM_014496 & 1.82 & 0.0029 \\
\hline PCDH11Y & NM_032971 & 1.69 & 0.0211 \\
\hline GABRE & U92285 & 1.64 & 0.0276 \\
\hline MGC35361 & AK298753 & 1.64 & 0.0076 \\
\hline KIAA1467 & NM_020853 & 1.63 & 0.0078 \\
\hline HIST1H2BK & NM_080593 & 1.61 & 0.0189 \\
\hline GABRA4 & NM_000809 & 1.58 & 0.0018 \\
\hline LOC441233 & AK128010 & 1.56 & 0.0321 \\
\hline PGAP1 & NM_024989 & 1.55 & 0.0004 \\
\hline LRP2 & NM_004525 & 1.55 & 0.0076 \\
\hline$A G L$ & NM_000028 & 1.53 & 0.0069 \\
\hline CCDC125 & NM_176816 & 1.53 & 0.0021 \\
\hline HYAL4 & NM_012269 & 1.53 & 0.0102 \\
\hline C9orf131 & AK090398 & 1.52 & 0.0034 \\
\hline
\end{tabular}

functional gene set found for unexplained FGR was "Insulin_Adip_Insens_dn" (Table 5). This indicates that the genes downregulated by insulin play a prominent role in FGR and hence that the insulin pathway is specifically activated in unexplained cases of this disorder [27]. For the pre-eclampsia group, "Kannan_P53_up", consisting of TP53-responsive genes, was the only gene set found to be enriched (Table 6) [28]. Among the 36 genes in this set, five genes (BCL6, ENG, SCGB2A2, $A D F P$ and NHLH2) were considered to contribute to the enrichment score (core enrichment), and the expression levels were significantly different in the genes BCL6, ENG, ADFP, BAX and PMAIP1 (Figure $3 \mathrm{~A})$. Clustering analysis using the total set of 36 genes assigned the pre-eclamptic samples and a subset of the unexplained FGR specimens to the same tree branches (Figure 3B). 
Table 4 The most highly differentially expressed genes common to pre-eclampsia and FGR

\begin{tabular}{|c|c|c|c|c|c|}
\hline Gene name & Genbank & $\begin{array}{c}\text { Fold-Change } \\
\text { (PE) } \\
\end{array}$ & $\begin{array}{c}P \text { Value } \\
(\mathrm{PE})\end{array}$ & $\begin{array}{c}\text { Fold-Change } \\
\text { (FGR) }\end{array}$ & $\begin{array}{c}P \text { Value } \\
\text { (FGR) }\end{array}$ \\
\hline \multicolumn{6}{|c|}{ Up-regulated genes } \\
\hline LEP & NM_000230 & 10.94 & $<0.0001$ & 3.56 & 0.0066 \\
\hline CGB & NM_000737 & 4.72 & 0.0011 & 2.50 & 0.0391 \\
\hline CGB5 & NM_033043 & 4.71 & 0.0012 & 2.46 & 0.0436 \\
\hline CGB1 & NM_033377 & 4.61 & 0.0010 & 2.38 & 0.0430 \\
\hline CGB7 & NM_033142 & 4.43 & 0.0012 & 2.37 & 0.0445 \\
\hline CGB2 & NM_033378 & 4.37 & 0.0007 & 2.37 & 0.0329 \\
\hline HTRA4 & NM_153692 & 4.00 & 0.0002 & 1.93 & 0.0471 \\
\hline $\mathrm{CRH}$ & NM_000756 & 3.66 & 0.0008 & 2.36 & 0.0191 \\
\hline PAPPA2 & NM_020318 & 2.55 & 0.0001 & 1.72 & 0.0125 \\
\hline NTRK2 & NM_006180 & 2.50 & $<0.0001$ & 1.58 & 0.0111 \\
\hline $\mathrm{CP}$ & NM_000096 & 2.44 & 0.0445 & 2.44 & 0.0446 \\
\hline FLT1 & NM_002019 & 2.39 & 0.0001 & 1.51 & 0.0347 \\
\hline HTRA1 & NM_002775 & 2.20 & 0.0015 & 1.67 & 0.0276 \\
\hline QPCT & NM_012413 & 2.12 & 0.0008 & 1.60 & 0.0240 \\
\hline ENG & NM_000118 & 2.03 & 0.0003 & 1.56 & 0.0143 \\
\hline \multicolumn{6}{|c|}{ Down-regulated genes } \\
\hline ACOXL & NM_001105516 & 2.39 & $<0.0001$ & 1.92 & 0.0003 \\
\hline GSTA3 & NM_000847 & 2.09 & 0.0014 & 1.60 & 0.0318 \\
\hline HIST1H1T & NM_005323 & 2.06 & 0.0003 & 2.03 & 0.0004 \\
\hline FAM26D & NM_153036 & 2.05 & 0.0009 & 1.83 & 0.0040 \\
\hline SNORD116 & AF241255 & 1.98 & 0.0203 & 2.07 & 0.0140 \\
\hline CATSPERB & NM_024764 & 1.98 & 0.0001 & 1.66 & 0.0023 \\
\hline WNT2 & NM_003391 & 1.97 & 0.0023 & 1.58 & 0.0301 \\
\hline MUC15 & NM_145650 & 1.89 & 0.0024 & 1.52 & 0.0371 \\
\hline SH3TC2 & NM_024577 & 1.89 & 0.0012 & 1.63 & 0.0092 \\
\hline C12orf39 & BC004336 & 1.85 & 0.0044 & 1.55 & 0.0366 \\
\hline TMEM136 & NM_174926 & 1.84 & $<0.0001$ & 1.61 & 0.0007 \\
\hline ZNF554 & NM_001102651 & 1.76 & 0.0005 & 1.71 & 0.0009 \\
\hline APLN & NM_017413 & 1.76 & 0.0007 & 1.65 & 0.0020 \\
\hline NAALADL2 & NM_207015 & 1.73 & 0.0039 & 1.71 & 0.0045 \\
\hline ZNF429 & NM_001001415 & 1.70 & 0.0027 & 1.56 & 0.0096 \\
\hline
\end{tabular}

Table 5 Gene sets enriched in FGR

\begin{tabular}{lcc}
\hline Gene set & Nominal $\boldsymbol{P}$ value & FDR \\
\hline Up-regulated; 315/984 & & \\
INSULIN_ADIP_INSENS_DN & $<0.0001$ & 0.237 \\
LIZUKA_G1_SM_G2 & $<0.0001$ & 0.272 \\
AGEING_KIDNEY_DN & $<0.0001$ & 0.529 \\
AGEING_KIDNEY_SPECIFIC_DN & $<0.0001$ & 0.643 \\
CMV_HCMV_TIMECOURSE_24HRS_UP & $<0.0001$ & 0.705 \\
BRACX_UP & $<0.0001$ & 0.814 \\
UNDERHILL_PROLIFERAION & $<0.0001$ & 0.820 \\
Down-regulated; 669/984 & & \\
IFNALPHA_RESIST_DN & $<0.0001$ & 1.000 \\
\hline
\end{tabular}

Nominal $P$ values $<1 \%$ are listed.
To confirm the activation of the TP53 pathway in preeclampsia, qRT-PCR for TP53-related genes was performed using an increased number of samples (41 preeclampsia, 16 FGR and 45 normotensive pregnancy specimens) to validate our microarray results. The expression of TP53 itself did not change among the three

\section{Table 6 Gene sets enriched in pre-eclampsia}

\begin{tabular}{lcc}
\hline Gene set & Nominal $P$ value & FDR \\
\hline Up-regulated; 315/984 & & \\
$\quad$ KANNAN_P53_UP & $<0.0001$ & 0.235 \\
Down-regulated; 669/984 & & \\
$\quad$ LIZUKA_G1_SM_G2 & 0.009 & 1.000 \\
$\quad$ DORSAM_HOXA9_UP & 0.009 & 1.000 \\
\hline
\end{tabular}

Nominal $P$ values $<1 \%$ are listed. 


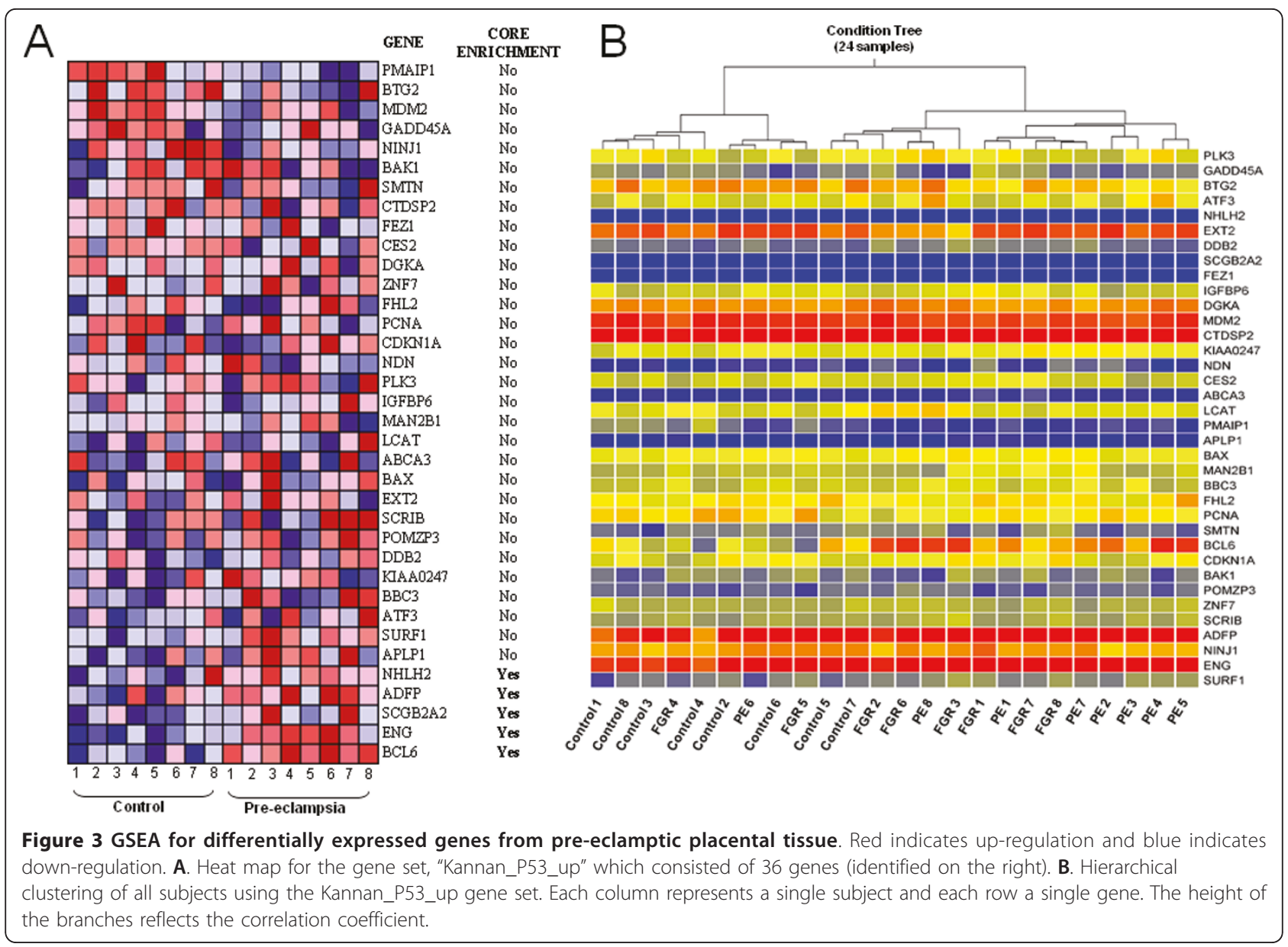

groups (Figure 4 and Additional file 4, Figure S1). However, a significant up-regulation of the downstream genes BCL6, ENG, ADFP, APLP1, SURF1 and BAX was confirmed in pre-eclampsia. Among these genes, the apoptosis-related genes $B C L 6, E N G$ and $B A X$ appeared to be upregulated also in unexplained FGR, but at lower levels compared with the pre-eclamptic placentas. Among the other genes related to apoptosis, FASLG and P53AIP1 were also found to be up-regulated in pre-eclampsia (Table 7). However, the genes encoding caspases were not up-regulated, suggesting that apoptosis itself is not executed in pre-eclampsia.

\section{Discussion}

To date, a large body of evidence has accumulated with regards to the global expression profiles of the preeclamptic placenta, and several important genes have been identified via this strategy $[16,29,30]$. On the other hand, although there are a comparable number of reports showing microarray analysis for the FGR placenta, these investigations have not been as effective in identifying potentially causative genes for this disease. Previous studies have documented that genes involved in hypoxia or metabolism-related genes are common to the group of differentially expressed genes in the FGR placenta [31-34]. However, these findings may require careful interpretation, since the expression of these genes is often affected by sampling site bias $[35,36]$. In addition, although the question of whether pre-eclampsia and FGR share a common etiology is not a longstanding issue, there have been few comparative expression profiles undertaken for these disorders, and the results are not consistent $[37,38]$.

In our current study, comparative analysis of the global expression profiles of pre-eclampsia and FGR indicate a common pathophysiology. This is based on our findings that 1) pre-eclampsia and a subset of FGR samples show a high correlation coefficient for their overall microarray data and are clustered into the same category, and 2) most of the genes known to be up-regulated in pre-eclampsia were found to be up-regulated in FGR. A possible interpretation might be that preeclampsia and a subset of FGR are in fact the same disorder with the same etiology, and that the apparent differences depend on the degree of severity. Alternatively, it is possible that these two disorders are related 


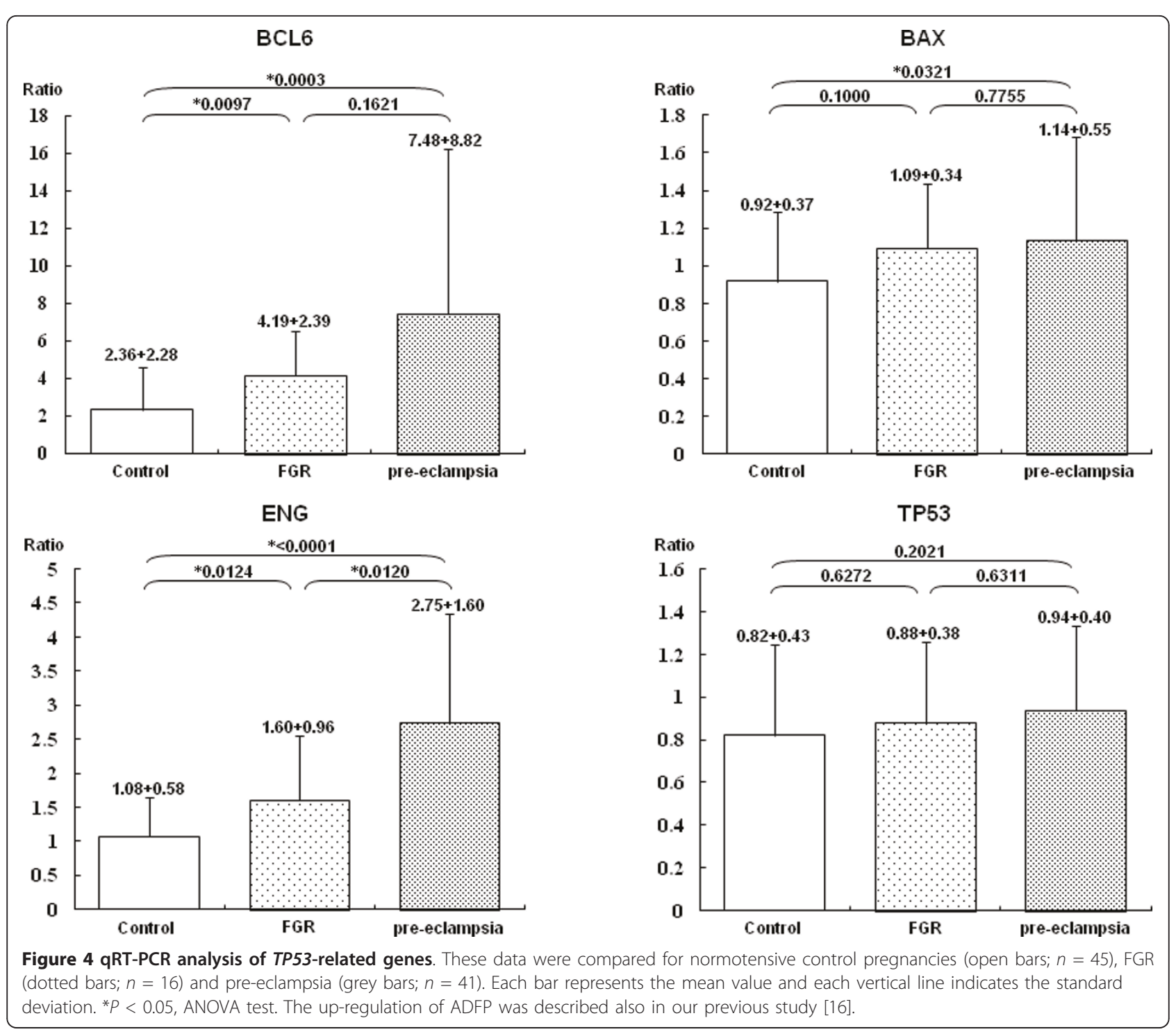

conditions with the same etiology and differing only by the presence of maternal hypertension.

It was important to then address whether the presence or absence of maternal symptoms determines the phenotypic difference between pre-eclampsia and unexplained FGR. Although standard GO analyses did not reveal specific biological processes or molecular functions, the data from GSEA analyses show that TP53 downstream genes are more highly activated in preeclampsia than in FGR. As TP53 itself is not up-regulated at the mRNA level, this activation is likely due to stabilization of the p53 protein, which has a known short half-life [39]. Up-regulated genes in pre-eclampsia also included $B A X$ and $B C L 6$, which are known to regulate apoptosis $[40,41]$. A prevailing hypothesis is that trophoblast hypoxia due to abnormal spiral arteries triggers apoptosis leading to the onset of pre-eclampsia
[42]. The TP53 pathway may contribute to this process. The current literature does not support the contribution of TP53 to pre-eclampsia but a considerable body of evidence indicates that the apoptosis of trophoblasts itself is increased in the pre-eclamptic placenta [43-45].

Our present data indicate that most of the genes known to be up-regulated in the placenta in preeclampsia are also up-regulated in unexplained FGR placentas. These genes include FLT1 and ENG, which encode soluble proteins that are detected in the maternal circulation and serve as anti-angiogenic factors [6,7]. These data are consistent with previously published findings [46-49]. Although conflicting data have also been reported [50,51], it might be possible that the FGR samples in these reports might be derived from lateonset cases that are fundamentally different at the molecular level [52]. High levels of these circulating factors 
Table 7 Microarray analysis of apoptosis-associated genes

\begin{tabular}{|c|c|c|c|}
\hline & $\begin{array}{l}\text { Control } \\
(n=8)\end{array}$ & $\begin{array}{c}\mathrm{PE} \\
(\mathrm{n}=8)\end{array}$ & $P$ value \\
\hline TP53 (NM_000546) & $8.04 \pm 0.10$ & $7.93 \pm 0.25$ & n.s. \\
\hline MDM2 (NM_002392) & $8.96 \pm 0.15$ & $8.79 \pm 0.20$ & n.s. \\
\hline FAS (NM_000043) & $6.44 \pm 0.19$ & $6.29 \pm 0.38$ & n.s. \\
\hline FASLG (NM_000639) & $5.25 \pm 0.09$ & $5.50 \pm 0.26$ & 0.030 \\
\hline BCL2 (NM_000633) & $8.42 \pm 0.16$ & $8.38 \pm 0.3$ & n.s. \\
\hline MCL1 (NM_021960) & $10.07 \pm 0.16$ & $10.05 \pm 0.27$ & n.s. \\
\hline BID (NM_197966) & $6.21 \pm 0.06$ & $6.21 \pm 0.15$ & n.s. \\
\hline BAD (NM_004322) & $7.16 \pm 0.10$ & $7.35 \pm 0.25$ & n.s. \\
\hline BAK1 (NM_001188) & $6.59 \pm 0.20$ & $6.51 \pm 0.26$ & n.s. \\
\hline CASP2 (NM_032982) & $7.81 \pm 0.07$ & $7.72 \pm 0.19$ & n.s. \\
\hline CASP3 (NM_004346) & $7.22 \pm 0.21$ & $7.11 \pm 0.25$ & n.s. \\
\hline CASP6 (NM_001226) & $4.71 \pm 0.3$ & $4.77 \pm 0.36$ & n.s. \\
\hline CASP7 (NM_033338) & $7.18 \pm 0.10$ & $7.17 \pm 0.25$ & n.s. \\
\hline CASP8 (NM_001228) & $6.75 \pm 0.14$ & $6.66 \pm 0.22$ & n.s. \\
\hline CASP9 (NM_001229) & $7.18 \pm 0.17$ & $7.18 \pm 0.19$ & n.s. \\
\hline CASP10 (NM_032977) & $5.58 \pm 0.14$ & $5.47 \pm 0.26$ & n.s. \\
\hline XIAP (NM_001167) & $7.09 \pm 0.23$ & $7.08 \pm 0.32$ & n.s. \\
\hline BIRC5 (NM_001168) & $5.97 \pm 0.23$ & $6.07 \pm 0.29$ & n.s. \\
\hline APAF1 (NM_181861) & $6.85 \pm 0.11$ & $6.82 \pm 0.36$ & n.s. \\
\hline P53AIP1 (NM_022112) & $4.16 \pm 0.14$ & $4.42 \pm 0.29$ & 0.025 \\
\hline
\end{tabular}

Data for normalized signal intensities are shown.

are likely to induce maternal systemic endothelial dysfunction. There is little doubt also that the apoptosis of trophoblasts is associated with cell turnover in the placental villi [53]. This apoptotic process halts at an early stage, and dissolution and fusion of the plasma membrane leads to generation of syncytiotrophoblasts, with accompanying microparticles shedding to the maternal circulation $[54,55]$. Excess shedding, possibly due to a hypoxia-induced increased turnover of syncytiotrophoblasts, is often observed in the pre-eclamptic placenta and manifests as syncytial knots [56]. It is possible therefore that an up-regulation of the TP53 pathway induces the deportation of microparticles, including high levels of anti-angiogenic factors, and that this might facilitate maternal systemic symptoms in preeclampsia $[57,58]$.

Several reports have now indicated that placentas from FGR pregnancies without pre-eclampsia also manifest increased apoptosis or the up-regulation of TP53 [59-61]. However, the levels of the apoptotic response in FGR appear to be less severe than in pre-eclampsia [62]. In this context, our present data suggest that a subset of unexplained FGR might possibly be pre-eclampsia with mild maternal symptoms that do not fit the currently accepted disease criteria. Our qRT-PCR data showing that TP53-downstream genes are highly up-regulated in pre-eclampsia and in some cases of unexplained FGR lend moderate support to this hypothesis. Hence, in spite of the preliminary nature of the study due to the small sample size, these data warrant further investigation.

\section{Additional material}

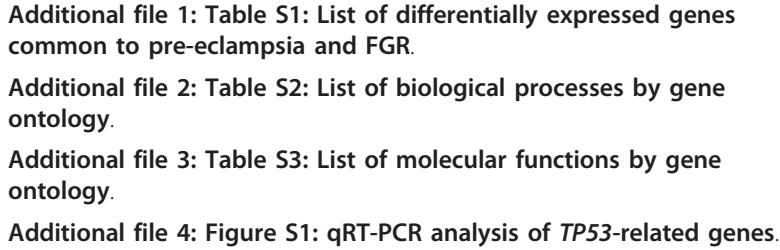

Additional file 2: Table S2: List of biological processes by gene ontology

Additional file 3: Table S3: List of molecular functions by gene ontology

Additional file 4: Figure S1: qRT-PCR analysis of TP53-related genes.

\section{Acknowledgements}

We thank the Institute of Bio-System Information, Tohoku Chemical Co. Ltd. for helpful discussions. This study is supported by the JAOG Ogyaa Donation Foundation, by the Hori Information Science Promotion Foundation, and by a grant-in-aid from the Ministry of Education, Culture, Sports, Science, and Technology of Japan (to H.K.).

\section{Author details}

Department of Obstetrics and Gynecology, Fujita Health University School of Medicine, Fujita Health University, Toyoake, Japan. ${ }^{2}$ Division of Molecular Genetics, Institute for Comprehensive Medical Science, Fujita Health University, Toyoake, Japan

\section{Authors' contributions}

$\mathrm{HN}$ conceived the project, participated in its design and coordination, and analyzed the data. SO, MS and TK carried out the overall molecular experiments including the microarray analysis. TS carried out the operations, and participated in the design and coordination of the study. HK conceived the project, participated in its design and coordination, and helped to draft the manuscript. YU participated in the design and coordination of the project and helped to draft the manuscript. All of the authors read and approved the final manuscript.

\section{Competing interests}

The authors declare that they have no competing interests.

Received: 5 April 2011 Accepted: 2 August 2011

Published: 2 August 2011

\section{References}

1. Sibai B, Dekker G, Kupferminc M: Pre-eclampsia. Lancet 2005, 365:785-799.

2. Hall DR, Odendaal HJ, Steyn DW, Grove D: Expectant management of early onset, severe pre-eclampsia: maternal outcome. BJOG 2000, 107:1252-1257.

3. Roberts JM, Cooper DW: Pathogenesis and genetics of pre-eclampsia. Lancet 2001, 357:53-56.

4. Woodage T, Venter JC, Broder S: Application of the human genome to obstetrics and gynecology. Clin Obstet Gynecol 2002, 45:711-732.

5. Kanter D, Lindheimer MD, Wang E, Borromeo RG, Bousfield $E$, Karumanchi SA, Stillman IE: Angiogenic dysfunction in molar pregnancy. Am J Obstet Gynecol 2010, 202:184.e1-5.

6. Levine RJ, Maynard SE, Qian C, Lim KH, England LJ, Yu KF, Schisterman EF, Thadhani R, Sachs BP, Epstein FH, Sibai BM, Sukhatme VP, Karumanchi SA: Circulating angiogenic factors and the risk of preeclampsia. N Engl J Med 2004, 350:672-683

7. Venkatesha S, Toporsian M, Lam C, Hanai J, Mammoto T, Kim YM, Bdolah Y, Lim KH, Yuan HT, Libermann TA, Stillman IE, Roberts D, D'Amore PA, Epstein FH, Sellke FW, Romero R, Sukhatme VP, Letarte M, Karumanchi SA: Soluble endoglin contributes to the pathogenesis of preeclampsia. Nat Med 2006, 12:642-649. 
8. Cetin I, Alvino G: Intrauterine growth restriction: implications for placental metabolism and transport. A review. Placenta 2009, 30(Suppl A):S77-82.

9. Villar J, Carroli G, Wojdyla D, Abalos E, Giordano D, Ba'aqeel H, Farnot U, Bergsjø P, Bakketeig L, Lumbiganon P, Campodónico L, Al-Mazrou Y, Lindheimer M, Kramer M, World Health Organization Antenatal Care Trial Research Group: Preeclampsia, gestational hypertension and intrauterine growth restriction, related or independent conditions? Am J Obstet Gynecol 2006, 194:921-931.

10. Kaufmann P, Black S, Huppertz B: Endovascular trophoblast invasion: implications for the pathogenesis of intrauterine growth retardation and preeclampsia. Biol Reprod 2003, 69:1-7.

11. Mayhew TM, Ohadike C, Baker PN, Crocker IP, Mitchell C, Ong SS: Stereological investigation of placental morphology in pregnancies complicated by pre-eclampsia with and without intrauterine growth restriction. Placenta 2003, 24:219-226.

12. Egbor M, Ansari T, Morris N, Green CJ, Sibbons PD: Morphometric placental villous and vascular abnormalities in early- and late-onset preeclampsia with and without fetal growth restriction. BJOG 2006, 113:580-589.

13. Cross JC: The genetics of pre-eclampsia: a feto-placental or maternal problem? Clin Genet 2003, 64:96-103.

14. ACOG Committee on Obstetric Practice: ACOG practice bulletin. Diagnosis and management of preeclampsia and eclampsia. Int J Gynaecol Obstet 2002, 77:67-75.

15. Ogawa Y, Iwamura T, Kuriya N, Nishida H, Takeuchi H, Takada M, Itabashi K, Imura S, Isobe K: Birth size standards by gestational age for Japanese neonates. Acta Neonat Jap 1998, 34:624-632.

16. Nishizawa H, Pryor-Koishi K, Kato T, Kowa H, Kurahashi H, Udagawa Y: Microarray analysis of differentially expressed fetal genes in placental tissue derived from early and late onset severe pre-eclampsia. Placenta 2007, 28:487-497.

17. Brazma A, Hingamp P, Quackenbush J, Sherlock G, Spellman P, Stoeckert C, Aach J, Ansorge W, Ball CA, Causton HC, Gaasterland T, Glenisson P, Holstege FC, Kim IF, Markowitz V, Matese JC, Parkinson H, Robinson A, Sarkans U, Schulze-Kremer S, Stewart J, Taylor R, Vilo J, Vingron M: Minimum information about a microarray experiment (MIAME)-toward standards for microarray data. Nat Genet 2001, 29:365-371.

18. Kim PM, Tidor B: Subsystem identification through dimensionality reduction of large-scale gene expression data. Genome Res 2003, 13:1706-1718.

19. Brunet JP, Tamayo P, Golub TR, Mesirov JP: Metagenes and molecular pattern discovery using matrix factorization. Proc Natl Acad Sci USA 2004, 101:4164-4169.

20. Mootha VK, Lindgren CM, Eriksson KF, Subramanian A, Sihag S, Lehar J, Puigserver P, Carlsson E, Ridderstråle M, Laurila E, Houstis N, Daly MJ, Patterson N, Mesirov JP, Golub TR, Tamayo P, Spiegelman B, Lander ES, Hirschhorn JN, Altshuler D, Groop LC: PGC-1alpha-responsive genes involved in oxidative phosphorylation are coordinately downregulated in human diabetes. Nat Genet 2003, 34:267-273.

21. Subramanian A, Tamayo P, Mootha VK, Mukherjee S, Ebert BL, Gillette MA, Paulovich A, Pomeroy SL, Golub TR, Lander ES, Mesirov JP: Gene set enrichment analysis: a knowledge-based approach for interpreting genome-wide expression profiles. Proc Natl Acad Sci USA 2005, 102:15545-15550.

22. Gene Set Enrichment Analysis (GSEA). [http://www.broad.mit.edu/gsea/]

23. Muttukrishna S, Knight PG, Groome NP, Redman CW, Ledger WL: Activin A and inhibin $A$ as possible endocrine markers for pre-eclampsia. Lancet 1997, 349:1285-1288.

24. Pryor-Koishi K, Nishizawa H, Kato T, Kogo H, Murakami T, Tsuchida K, Kurahashi H, Udagawa Y: Overproduction of the follistatin-related gene protein in the placenta and maternal serum of women with preeclampsia. BJOG 2007, 114:1128-1137.

25. McCarthy JF, Misra DN, Roberts JM: Maternal plasma leptin is increased in preeclampsia and positively correlates with fetal cord concentration. Am J Obstet Gynecol 1999, 180:731-736.

26. Nishizawa H, Pryor-Koishi K, Suzuki M, Kato T, Kogo H, Sekiya T, Kurahashi H, Udagawa Y: Increased levels of pregnancy-associated plasma protein-A2 in the serum of pre-eclamptic patients. Mol Hum Reprod 2008, 14:595-602.
27. Sartipy $P$, Loskutoff DJ: Expression profiling identifies genes that continue to respond to insulin in adipocytes made insulin-resistant by treatment with tumor necrosis factor-alpha. J Biol Chem 2003, 278:52298-52306.

28. Kannan K, Amariglio N, Rechavi G, Jakob-Hirsch J, Kela I, Kaminski N, Getz G, Domany E, Givol D: DNA microarrays identification of primary and secondary target genes regulated by p53. Oncogene 2001, 20:2225-2234

29. Maynard SE, Min JY, Merchan J, Lim KH, Li J, Mondal S, Libermann TA Morgan JP, Sellke FW, Stillman IE, Epstein FH, Sukhatme VP, Karumanchi SA: Excess placental soluble fms-like tyrosine kinase 1 (sFlt1) may contribute to endothelial dysfunction, hypertension, and proteinuria in preeclampsia. J Clin Invest 2003, 111:649-658.

30. Enquobahrie DA, Meller M, Rice K, Psaty BM, Siscovick DS, Williams MA: Differential placental gene expression in preeclampsia. Am J Obstet Gynecol 2008, 199:566.e1-11.

31. Roh CR, Budhraja V, Kim HS, Nelson DM, Sadovsky Y: Microarray-based identification of differentially expressed genes in hypoxic term human trophoblasts and in placental villi of pregnancies with growth restricted fetuses. Placenta 2005, 26:319-328.

32. Okamoto A, Endo H, Kalionis B, Shinya M, Saito M, Nikaido T, Tanaka T: IGFBP1 and Follistatin-like 3 genes are significantly up-regulated in expression profiles of the IUGR placenta. Placenta 2006, 27:317-321.

33. McCarthy C, Cotter FE, McElwaine S, Twomey A, Mooney EE, Ryan F, Vaughan J: Altered gene expression patterns in intrauterine growth restriction: potential role of hypoxia. Am J Obstet Gynecol 2007, 196:70. e1-6.

34. Struwe E, Berzl G, Schild R, Blessing H, Drexel L, Hauck B, Tzschoppe A, Weidinger M, Sachs M, Scheler C, Schleussner E, Dötsch J: Microarray analysis of placental tissue in intrauterine growth restriction. Clin Endocrinol 2010, 72:241-247.

35. Wyatt SM, Kraus FT, Roh CR, Elchalal U, Nelson DM, Sadovsky Y: The correlation between sampling site and gene expression in the term human placenta. Placenta 2005, 26:372-379.

36. Tzschoppe AA, Struwe E, Dörr HG, Goecke TW, Beckmann MW, Schild RL, Dötsch J: Differences in gene expression dependent on sampling site in placental tissue of fetuses with intrauterine growth restriction. Placenta 2010, 31:178-185.

37. Vaiman D, Mondon F, Garcès-Duran A, Mignot TM, Robert B, Rebourcet R,

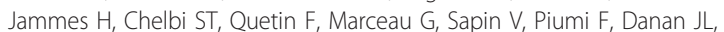
Rigourd V, Carbonne B, Ferré F: Hypoxia-activated genes from early placenta are elevated in preeclampsia, but not in Intra-Uterine Growth Retardation. BMC Genomics 2005, 6:111.

38. Toft JH, Lian IA, Tarca AL, Erez O, Espinoza J, Eide IP, Bjørge L, Draghici S, Romero R, Austgulen R: Whole-genome microarray and targeted analysis of angiogenesis-regulating gene expression (ENG, FLT1, VEGF, PIGF) in placentas from pre-eclamptic and small-for-gestational-age pregnancies. J Matern Fetal Neonatal Med 2008, 21:267-273.

39. An WG, Kanekal M, Simon MC, Maltepe E, Blagosklonny MV, Neckers LM: Stabilization of wild-type p53 by hypoxia-inducible factor 1alpha. Nature 1998, 392:405-408.

40. Miyashita T, Krajewski S, Krajewska M, Wang HG, Lin HK, Liebermann DA, Hoffman B, Reed JC: Tumor suppressor p53 is a regulator of bcl-2 and bax gene expression in vitro and in vivo. Oncogene 1994, 9:1799-1805.

41. Albagli-Curiel O: Ambivalent role of BCL6 in cell survival and transformation. Oncogene 2003, 22:507-516.

42. Levy R, Nelson DM: To be, or not to be, that is the question. Apoptosis in human trophoblast. Placenta 2000, 21:1-13.

43. Jeschke U, SchiessI B, Mylonas I, Kunze S, Kuhn C, Schulze S, Friese K, Mayr D: Expression of the proliferation marker Ki-67 and of p53 tumor protein in trophoblastic tissue of preeclamptic, HELLP, and intrauterine growth-restricted pregnancies. Int J Gynecol Pathol 2006, 25:354-360.

44. Allaire AD, Ballenger KA, Wells SR, McMahon MJ, Lessey BA: Placental apoptosis in preeclampsia. Obstet Gynecol 2000, 96:271-276.

45. Leung DN, Smith SC, To KF, Sahota DS, Baker PN: Increased placental apoptosis in pregnancies complicated by preeclampsia. Am J Obstet Gynecol 2001, 184:1249-1250.

46. Stepan H, Geide A, Faber R: Soluble fms-like tyrosine kinase 1. N Engl J Med 2004, 351:2241-2242.

47. Stepan H, Krämer T, Faber R: Maternal plasma concentrations of soluble endoglin in pregnancies with intrauterine growth restriction. J Clin Endocrinol Metab 2007, 92:2831-2834. 
48. Nevo O, Many A, Xu J, Kingdom J, Piccoli E, Zamudio S, Post M, Bocking A, Todros T, Caniggia I: Placental expression of soluble fms-like tyrosine kinase 1 is increased in singletons and twin pregnancies with intrauterine growth restriction. J Clin Endocrinol Metab 2008, 93:285-292.

49. Yinon Y, Nevo O, Xu J, Many A, Rolfo A, Todros T, Post M, Caniggia I: Severe intrauterine growth restriction pregnancies have increased placental endoglin levels: hypoxic regulation via transforming growth factor-beta 3. Am J Pathol 2008, 172:77-85.

50. Shibata E, Rajakumar A, Powers RW, Larkin RW, Gilmour C, Bodnar LM, Crombleholme WR, Ness RB, Roberts JM, Hubel CA: Soluble fms-like tyrosine kinase 1 is increased in preeclampsia but not in normotensive pregnancies with small-for-gestational-age neonates: relationship to circulating placental growth factor. J Clin Endocrinol Metab 2005, 90:4895-4903

51. Jeyabalan A, McGonigal S, Gilmour C, Hubel CA, Rajakumar A: Circulating and placental endoglin concentrations in pregnancies complicated by intrauterine growth restriction and preeclampsia. Placenta 2008, 29:555-563.

52. Rajakumar A, Jeyabalan A, Markovic N, Ness R, Gilmour C, Conrad KP: Placental HIF-1 alpha, HIF-2 alpha, membrane and soluble VEGF receptor-1 proteins are not increased in normotensive pregnancies complicated by late-onset intrauterine growth restriction. Am J Physiol Regul Integr Comp Physiol 2007, 293:766-774.

53. Crocker I: Gabor Than Award Lecture 2006: pre-eclampsia and villous trophoblast turnover: perspectives and possibilities. Placenta 2007, 28 S4-13.

54. Huppertz B, Frank HG, Kingdom JC, Reister F, Kaufmann P: Villous cytotrophoblast regulation of the syncytial apoptotic cascade in the human placenta. Histochem Cell Biol 1998, 110:495-508.

55. Mayhew TM, Leach L, McGee R, Ismail WW, Myklebust R, Lammiman MJ: Proliferation, differentiation and apoptosis in villous trophoblast at 13-41 weeks of gestation (including observations on annulate lamellae and nuclear pore complexes). Placenta 1999, 20:407-422.

56. Goswami D, Tannetta DS, Magee LA, Fuchisawa A, Redman CW, Sargent IL, von Dadelszen P: Excess syncytiotrophoblast microparticle shedding is a feature of early-onset pre-eclampsia, but not normotensive intrauterine growth restriction. Placenta 2006, 27:56-61.

57. Sargent IL, Germain SJ, Sacks GP, Kumar S, Redman CW: Trophoblast deportation and the maternal inflammatory response in pre-eclampsia. $J$ Reprod Immunol 2003, 59:153-160.

58. Heazell AE, Crocker IP: Live and let die - regulation of villous trophoblast apoptosis in normal and abnormal pregnancies. Placenta 2008, 29:772-783.

59. Smith SC, Baker PN, Symonds EM: Increased placental apoptosis in intrauterine growth restriction. Am J Obstet Gynecol 1997, 177:1395-1401.

60. Levy R, Smith SD, Yusuf K, Huettner PC, Kraus FT, Sadovsky Y, Nelson DM: Trophoblast apoptosis from pregnancies complicated by fetal growth restriction is associated with enhanced p53 expression. Am J Obstet Gynecol 2002, 186:1056-1061.

61. Axt R, Kordina AC, Meyberg R, Reitnauer K, Mink D, Schmidt W: Immunohistochemical evaluation of apoptosis in placentae from normal and intrauterine growth-restricted pregnancies. Clin Exp Obstet Gynecol 1999, 26:195-198.

62. Ishihara N, Matsuo H, Murakoshi H, Laoag-Fernandez JB, Samoto T, Maruo T: Increased apoptosis in the syncytiotrophoblast in human term placentas complicated by either preeclampsia or intrauterine growth retardation. Am J Obstet Gynecol 2002, 186:158-166.

doi:10.1186/1477-7827-9-107

Cite this article as: Nishizawa et al:: Comparative gene expression profiling of placentas from patients with severe pre-eclampsia and unexplained fetal growth restriction. Reproductive Biology and Endocrinology 2011 9:107.

\section{Submit your next manuscript to BioMed Central and take full advantage of:}

- Convenient online submission

- Thorough peer review

- No space constraints or color figure charges

- Immediate publication on acceptance

- Inclusion in PubMed, CAS, Scopus and Google Scholar

- Research which is freely available for redistribution

Submit your manuscript at www.biomedcentral.com/submit
Biomed Central 